\title{
Uterine prolapse and urinary tract obstruction
}

\author{
J B YOUNG, P L SELBY, M PEACOCK, A M BROWNJOHN
}

Brettauer and Rubin drew attention to uterine prolapse as a cause of urinary tract obstruction for the first time in the English literature in 1923.1 Several other reports followed, but the importance of this association is not widely appreciated and has been neglected in many standard medical and gynaecological textbooks. We describe two cases in which uterine prolapse caused renal failure and in which simple measures restored renal function to normal.

\section{Case reports}

CASE 1

A frail 79 year old woman was admitted with a three day history of increasingly severe right loin pain associated with vomiting, fever, and rigors. She had not passed any urine over the preceding 12 hours. There was no history of urinary tract disease. On examination she showed signs of salt and water depletion and blood pressure was $80 / 50 \mathrm{~mm} \mathrm{Hg}$. There was considerable tenderness over the right renal angle, and she had a procidentia that had been present for several years.

Septic shock due to acute pyelonephritis was diagnosed, and investigations showed a haemoglobin concentration of $12.6 \mathrm{~g} / \mathrm{dl}$ and white cell count of $31.5 \times 10^{9} / 1\left(80^{\circ} \%\right.$ neutrophils). Plasma electrolyte concentrations were normal, but the urea concentration was $18.8 \mathrm{mmol} / 1$ $(113 \mathrm{mg} / 100 \mathrm{ml})$ and the creatinine concentration $297 \mu \mathrm{mol} / 1$ $(3.4 \mathrm{mg} / 100 \mathrm{ml})$. Catheterisation of the bladder yielded $50 \mathrm{ml}$ of purulent urine, from which coliform organisms sensitive to ampicillin were subsequently isolated. She was resuscitated with intravenous fluids, and treatment with intravenous ampicillin was started; although her blood pressure increased, no further urine was produced.

Intravenous urography was performed after rehydration. This showed considerable delay in the pyelogram phase with dilatation of the pelvicaliceal systems and the ureters, which had been pulled downward through the pelvic outlet by the prolapse. As the urinary obstruction was thought to be due to the prolapse this was manually replaced and a ring pessary inserted. Immediate drainage of urine occurred, and renal function returned to normal over the next few days. She was discharged with the ring pessary in place, and renal function remained normal without recurrence of urinary infection.

\section{CASE 2}

A 79 year old woman presented as an emergency with bronchopneumonia and was incidentally found to be thyrotoxic and to have

Renal Unit, General Infirmary, Leeds LS1 3EX

J B YOUNG, MB, MRCP, registrar

A M BROWNJOHN, MB, MRCP, consultant

\footnotetext{
Medical Research Council Mineral Metabolism Unit, Leeds General Infirmary

P L SELBY, MA, MRCP, registrar

$M$ PEACOCK, MB, FRCP, consultant

Correspondence to: Dr J B Young.
}

Uterine prolapse is a potentially reversible but often overlooked cause of renal failure

an asymptomatic procidentia. During the course of follow up for the thyroid condition her prolapse began to cause discomfort and she was therefore referred for consideration of surgical repair. During preoperative investigation it was found that her plasma creatinine concentration had risen over the course of the year from $55 \mu \mathrm{mol} / \mathrm{l}$ $(0.6 \mathrm{mg} / 100 \mathrm{ml})$ to $289 \mu \mathrm{mol} / 1(3.3 \mathrm{mg} / 100 \mathrm{ml})$ with a concomitant decrease in creatinine clearance from 85 to $6 \mathrm{ml} / \mathrm{min}$. There was no evidence of urinary tract infection.

Intravenous urography showed bilateral hydronephrosis with dilated ureters prolapsing out from the pelvis. On correction of the anatomical abnormality with a shelf pessary renal function improved and the plasma creatinine concentration fell to $156 \mu \mathrm{mol} / 1(1.8 \mathrm{mg} /$ $100 \mathrm{ml})$. After a definitive surgical repair renal function improved further and the creatinine concentration fell to $105 \mu \mathrm{mol} / 1(1.2 \mathrm{mg} /$ $100 \mathrm{ml}$ ).

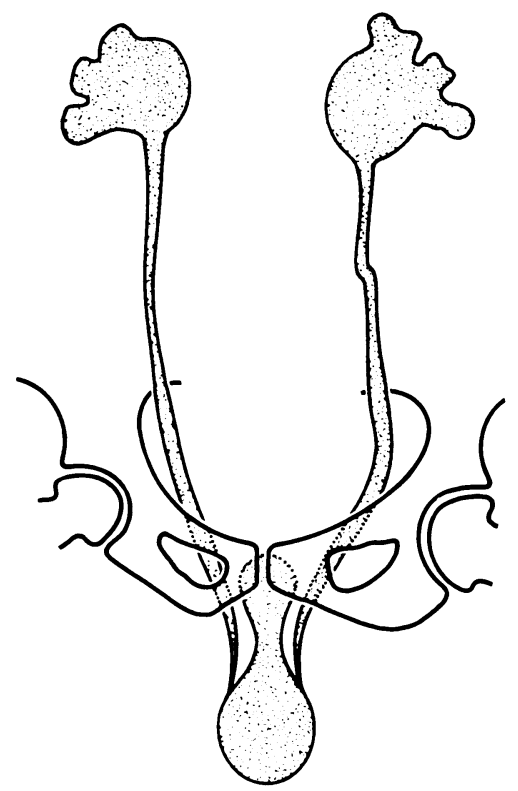

Typical appearance of intravenous urogram in cases of urinary tract obstruction due to uterine prolapse. Bilateral hydronephrosis is present with dilated ureters, the lower ends of which are displaced out from the pelvis together with the bladder, which has an "hour glass" appearance.

\section{Comment}

Prolapse of the uterus is an important cause of urinary tract disease. It predisposes to incontinence and to urinary infection, which is often recurrent, ${ }^{2}$ and may also produce renal failure due to obstruction. ${ }^{3}$ The diagnosis is often overlooked until 
suggested by an intravenous urogram showing bilateral hydronephrosis and hydroureter with descent of the bladder and lower ureters into the prolapse. ${ }^{45}$ The bladder often has a characteristic deformity, with a waisted or "hour glass" appearance (figure).

The association of prolapse and urinary disease is well described, but the diagnosis is often delayed or neglected. This may in part be due to the scant attention it receives in most standard textbooks, which is unfortunate as simple measures may reverse potentially serious renal disease. In case 1 the relevance of the prolapse was not appreciated until after intravenous urography. The simple procedure of uterine replacement and insertion of a ring pessary reversed the urinary obstruction and renal failure. In case 2 the patient had probably suffered from some degree of urinary tract obstruction for a considerable time. Nevertheless, prompt improvement occurred after correction of the anatomical abnormality.

Hydronephrosis may be seen in association with any degree of prolapse but is much more common in complete procidentia. ${ }^{6}$ The mechanism of obstruction is not clear. Possible factors include compression of the ureters by the uterine vessels, ${ }^{1}$ the levator ani sling, ${ }^{7}$ or even the uterine fundus. ${ }^{8}$ Recurrent urinary infection is a common complication of genital prolapse ${ }^{25}$ and may be attributable to stasis of urine in the obstructed ureters and the bladder. The contribution of bladder stasis is uncertain, however, as the evidence for an increased residual volume is conflicting. ${ }^{25}$ The altered anatomy may also predispose to entry of infection.

These cases emphasise the need for any woman with un- explained disease of the urinary tract to undergo pelvic examination to exclude a prolapse that might prove a readily treatable cause of the disease. Furthermore, women with procidentia should undergo tests of renal function and renal ultrasonography or intravenous urography to exclude obstruction of the urinary tract.

We are grateful to the department of medical illustration, University of Leeds, for drawing the figure.

\section{References}

${ }^{1}$ Brettauer J, Rubin IC. Hydroureter and hydronephrosis: a frequent secondary finding in cases of prolapse of the uterus and bladder. $A m \mathcal{F}$ Obstet Gynecol 1923;6:696-708.

2 Sourander LB, Ruikka I, Gronroos M. Correlation between urinary tract infection, prolapse conditions and function of the bladder in aged female hospital patients. Gerontologia Clinica 1965;7:179-84.

${ }^{3}$ Nassberger L, Larsson R. End-stage chronic renal failure due to total uterine prolapse. Acta Obstet Gynecol Scand 1982;61:495-7.

4 Stabler J. Uterine prolapse and urinary tract obstruction. Br $\mathcal{F}$ Radiol $1977 ; 50: 493-8$.

${ }^{5}$ Jones JB, Evison G. Excretion urography before and after surgical treatment of procedentia. Br $\mathcal{F}$ Obstet Gynaecol 1977;84:304-8.

${ }^{6}$ Klempner E. Gynecological lesions and ureterohydronephrosis. Am $\mathfrak{f}$ Obstet Gynecol 1952;64:1232-41.

${ }^{7}$ Halban J, Tandler J. Anatomie und Ätiologie der Genitalprolapse beim Weibe. Vienna and Leipzig: W Braumuller, 1907:176-80.

${ }^{8}$ Hadar H, Meiraz D. Total uterine prolapse causing hydroureteronephrosis. Surg Gynecol Obstet 1980;150:711-4.

(Accepted 31 fanuary 1984)
Beta blocking drugs are reported as possibly worsening a person's driving performance, so is it wise to give propranolol $(40 \mathrm{mg})$ to individuals about to take a driving test?

Beta blocking drugs will tend to reduce some of the peripheral effects caused by anxiety, most notably preventing the usual tachycardia. Many people find that these peripheral effects cause a deterioration in their performance and tend to think that they perform better when taking a beta blocker. Undoubtedly, beta blockers will also tend to dampen a person's effort, and many people perform best when stimulated by catecholamine drive. Driving is a particular point, when tiredness and general slowing of responses may be very detrimental to a subject, who may need all his faculties to act rapidly in unpredictable circumstances. I would not really think that it is wise, therefore, to give individuals propranolol before taking their driving test.-KIM FOX, consultant cardiologist, London.

What steps should be taken to determine the cause of confusion in elderly patients?

Confusion in the strict medical sense is the hallmark of the organic brain syndrome and is best assessed by testing the patient's memory for recent events-for instance, age, the day, the date, whereabouts, and any personal event of the past few days that can be corroborated. Performance may also be impaired by deafness, dysphasia, distraction by pain or fear, or poor motivation or concentration. The questions must therefore be kept as simple and as few as possible and more weight put on one or two correct answers than an overall score. If organic impairment is confirmed get a history from a relative or friend as to the duration or any recent exacerbation of the confusion. Gradual decline over weeks or months signifies dementia (which is so common that we can really only afford to investigate in depth if there are definite pointers towards the rarer treatable causes-for instance, $\mathrm{B}_{12}$ or thyroid deficiency, a subdural lesion, normal pressure hydrocephalus, epilepsy, cardiac arrhythmia). Onset or exacerbation of confusion over the past few days or weeks should prompt a search for an underlying physical illness (often mild) or drug toxicity. Specific treatment of the cause should allow the confusion to settle in the wake of the physical recovery. When recovery is slower or incomplete, you will usually have to postulate a cerebrovascular accident or look again more closely for an atypical functional illness. Mania triggered by a physical illness or operation can easily be mistaken for an acute confusional state but unlike the latter it fails to settle with the physical recovery. Behind the disturbed behaviour and conversation it is usually also possible to detect a reasonable grasp of whereabouts and recent personal events. The same applies with atypical depressive illness when the disturbance of mood should be the clue and will often have been noticed by relatives. Paranoid states are distinguishable by the predominance of auditory as compared with visual hallucinations. Auditory and visual hallucinations may also coexist with dementia but are still treatable in their own right.-COLIN GODBER, consultant psychogeriatrician, Southampton.

What treatment is advised for a 70 year old patient with severe bilateral tinnitus uncontrolled by prochlorperazine or trifluoperazine?

Tinnitus almost always results from a hearing defect, no matter how slight. The first requirement in management is with the aid of an otolaryngologist to establish the type of deafness. The most likely cause of bilateral tinnitus in a man aged 70 is senile presbyacusis, no matter how slight. The severity and reaction to tinnitus are largely subjective. No drug treatment is known to have a lasting effect and drugs tend to act more in the nature of a placebo. Tinnitus is most noticeable in a quiet environment, and the presence of a background noise often obliterates it and distracts the patient's attention. In the aged loneliness and fear play a great part in the patient's subjective reaction, for the aged live in a relatively quiet environment, have few interesting activities, do little more than listen to the tinnitus, fear the worst, and dwell on the consequences. Reassurance, interesting company, an active life, and the presence of a background noise help allay the fears and help the patient to adapt to the constant irritation of tinnitus as indeed he must. Tinnitus maskers sometimes help but in my experience occasional counselling with re-enforcement of the patient and his family and deliberately persuading him that tinnitus holds no threat is of the greatest benefit in management. An otolaryngologists's help may be required in managing the patient and perhaps on his advice reference to the local club of the British Tinnitus Association may help.-J D K DAWES, reader in otorhinolaryngology, Newcastle upon Tyne. 